\title{
STATUS OF ARSENIC CONTAMINATION AND ASSESSMENT OF OTHER PROBABLE HEAVY METAL CONTAMINANTS IN GROUND WATER OF DANG DISTRICT IN NEPAL
}

\author{
R.K. Mahat* and R.P. Kharel* \\ *Department of Water Supply and Sewerage (DWSS), Kathmandu, Nepal.
}

\begin{abstract}
Issue of arsenic contamination in drinking water in Terai belt has been a prevalent phenomenon in Nepal. So, this study has been conducted to visualize the status of arsenic contamination in ground water in Dang district located at central west Terai in Nepal. A total of 26,878 Tubewells and Dugwells were tested in 36 Village Development Committees (VDCs) using HACH arsenic testing field kit and 811 samples were re-tested employing Wagtech Digital Arsenator. 540 samples were analysed for confirmation by continuous flow Hydride Generation Technique using Atomic Absorption Spectrophotometer (AAS) in the DWSS laboratory. Of the total samples, $0.83 \%$ was found to contain Arsenic above WHO drinking water Qualty guidelines value of $0.01 \mathrm{mg} / \mathrm{l}(10 \mathrm{ppb})$ and $0.2 \%$ was found to contain arsenic above National Drinking Water Quality Guidelines value of $50 \mathrm{ppb}$. Gobardiha and Gangaparaspur are the two most affected VDCs with 1.75 and 1.16 percents of Tubewells being affected by arsenic of concentration above $50 \mathrm{ppb}$. The highest Arsenic concentration of $150 \mathrm{ppb}$ was found in Bela and Gobardiha VDCs and a severe case of Arsenicosis was identified in Bela VDC. 20 samples were randomly chosen and analyzed for other heavy and trace metal contaminants like $\mathrm{Cu}, \mathrm{Fe}, \mathrm{Mn}$, and $\mathrm{Cd}$ using flame AAS method. Ground water in this area seems to be affected by high concentration of Iron upto $11.01 \mathrm{mg} / \mathrm{l}$ and of Manganese upto $0.51 \mathrm{mg} / \mathrm{l}$. Statistical tools were employed to assess the probable association among them but no significant correlation among arsenic and other metals could be retrieved.
\end{abstract}

Keywords: Atomic Absorption; Spectrophotometry; Standard Reduction Potential; Arsenicosis; Heavy and Trace metals.

\section{INTRODUCTION}

Arsenic is a metalloid presented at the group 15 of the modern Periodic Table. Physically, arsenic occurs in many allotropic forms and in oxidation states of -III (as in $\mathrm{AsH}_{3}$ ), + III (as Arsenites) and $+\mathrm{V}$ (as arsenates, most stable form). Pentavalent form having Standard Reduction Potential of $0.56 \mathrm{~V}$ is strongly reduced to trivalent form. The ability of arsenic to undergo redox conversion between As(III) and As(V) makes its availability in the environment more abundant ${ }^{4}$. It forms colourless, tasteless, and odourless crystalline oxides $\mathrm{As}_{2} \mathrm{O}_{3}$ and $\mathrm{As}_{2} \mathrm{O}_{5}$ which are hygroscopic and readily soluble in water to form weak acidic solutions of. Arsenic (V) acid $\left(\mathrm{H}_{3} \mathrm{AsO}_{4}\right)$. Arsenic is highly toxic element and regarded as the king of poisons. Chemically, it is found in both organic and inorganic forms and the latter is more toxic and the trivalent form is more poisonous. International Agency for Research in Cancer (IARC) has identified it as a group 1 carcinogen. WHO (1993) has recommended a tolerable concentration of arsenic to be $10 \mathrm{ppb}(0.01 \mathrm{mg} / \mathrm{L})$ and Nepal Government in 2006 has formulated a National Drinking Water
Quality Guidelines which has fixed the maximum concentration of arsenic in drinking water to be $50 \mathrm{ppb}$.

Arsenic is abundantly distributed in earth's crust (52nd in abundance $)^{3}$ in the form of minerals viz. arsenopyrite, realgar $\left(\mathrm{As}_{4} \mathrm{~S}_{4}\right)$, and orpiment $\left(\mathrm{As}_{2} \mathrm{~S}_{3}\right)$ etc. Due to weathering and other process like fragmentation of arsenic rich rocks and minerals it is introduced to water, ground water, and soil and sediments. Ground water in Indian sub continent especially Bangladesh, West Bengal (India) and Terai belt of Nepal is severely contaminated with arsenic. Although arsenic is essential to body in ultra trace amount, it is physiologically highly deleterious if consumed in high concentration. Concentration of Arsenic in $100 \mathrm{ppb}$ is considered to have lethal impact on human as well as animal health. Arsenic being effective carcinogen causes Keratosis, and Melanoma and in severe cases: Arsenicosis. It is the condition in which arsenic is deposited to skin, hair, and nails where it is firmly bounded to keratin. It also has Teratogenic effect. If consumed in high concentration for prolonged period, it may also be found in liver, kidney, spleen, and lungs as well. This

Author for Correspondence: R.K. Mahat, Department of Water Supply and Sewerage (DWSS), Kathmandu, Nepal. 
eventually can lead to severe renal and pulmonary dysfunction and even skin cancer. In Nepal, 400 cases of Arsenicosis have been reported in $2006^{7}$.

Sometimes, Arsenic may be associated with some other heavy and Trace metal contaminants like Cadmium, Manganese, Iron, Copper etc. their presence in intolerable limits can produce even more rigorous effects upon human health. Concerning these facts a research was conducted to assess the presence of probable contaminants along with Arsenic.

\section{MATERIALS AND METHODS}

26,878 water samples of tube wells and dug wells from 36 VDCs in Dang district were tested in field by employing HACH Arsenic field test kit. Of which, 811 samples were retested for confirmation in field by using WAGTECH Digital Arsenator. Again, 540 of the sample were transported to Central Drinking Water Quality Testing Laboratory for the cross checking purpose. Out of 540 samples, 20 samples were chosen randomly and administered to analyze other metal parameters like Iron, Copper, Manganese, and Cadmium.

\section{Sample collection}

Water samples were collected in the field in acid rinsed Polythene bottle of capacity $125 \mathrm{ml}$. About $1 \mathrm{ml}$ of concentrated hydrochloric acid of analytical grade, just enough to adjust sample $\mathrm{pH}$ below 2, was used to preserve the sample and transported to the central laboratory of DWSS.

\section{Analytical Procedure}

In laboratory, water samples were analyzed by Atomic Absorption Spectrophotometer (Thermo SOLAAR) employing Continuous flow hydride generation technique for Arsenic and other parameters were tested by simple flame method. All the analyses were carried out adopting Standard Methods of Analysis formulated by APHA and NASC. Chemicals and reagents used in the analysis were of analytical grade, double distilled water was used for solution preparation. Water samples, for testing Arsenic, were pretreated prior to analysis adding $5 \mathrm{ml}$ each of conc. $\mathrm{HCl}$ and $10 \%(\mathrm{v} / \mathrm{v}) \mathrm{NaI}$ and kept for about 20 minutes. On the other hand, water samples were undergone acid digestion for analysis of other metals. Linear calibration curve method using three standard metal solutions was employed to carry out the analysis.

\section{Chemistry of Arsenic Analysis}

In $50 \mathrm{ml}$ of a sample $5 \mathrm{ml}$ each of conc. $\mathrm{HCl}$ and $10 \% \mathrm{w} / \mathrm{v} \mathrm{NaI}$ are added. As a result, all arsenic species, both As(III) and As(V) , are converted into Arsenic (III) Tri-Iodide which on reaction with $0.5 \%$ Sodium Borohydride $\left(\mathrm{NaBH}_{4}\right)$ solution in acidic medium ( $50 \% \mathrm{v} / \mathrm{v} \mathrm{HCl}$ ) gives Arsine gas $\left(\mathrm{AsH}_{3}\right)$. Arsine is stable kinetically but not thermodynamically. So, it readily changes to Arsenic in flame ${ }^{1}$ which gives absorbance at $193.7 \mathrm{~nm}$.

$$
\begin{aligned}
& \mathrm{As}(\mathrm{III}) \text { and } \mathrm{As}(\mathrm{V}) \stackrel{\mathrm{NaI} / \mathrm{H}^{+}}{\longrightarrow} \mathrm{AsI}_{3} \text { (Reduction of As(V) into As(III)) } \\
& \mathrm{H}^{+} \\
& 4 \mathrm{AsI}_{3}+3 \mathrm{NaBH}_{4} \quad 4 \mathrm{AsH}_{3}+3 \mathrm{NaI}+3 \mathrm{BI}_{3} \text { (Arsine Generation) } \\
& 2 \mathrm{AsH}_{3} \quad 2 \mathrm{As}+3 \mathrm{H}_{2} \text { (Thermal Decomposition of Arsine into Arsenic) } \\
& \text { Heat }
\end{aligned}
$$

\section{RESULT AND DISCUSSIONS}

A total of 26,878 Ground Water samples from 36 VDCs were tested for arsenic in field level and $99.17 \%$ of them were found to be within $10 \mathrm{ppb}$ concentration, $0.63 \%$ of them found to contain arsenic concentration of 11-50 ppb which is above WHO tolerable limit and $0.2 \%$ were found to contain arsenic concentration more than 50 ppb violating National Drinking Water Quality Guidelines Value for arsenic. Of 41 VDCs of Dang, 5 VDCs contain no ground water source for drinking purpose and among rest of 36 VDCs: 17 VDCs possess ground water concentration of arsenic upto $10 \mathrm{ppb}$ ie safe, $10 \mathrm{VDCs}$

\begin{tabular}{|c|c|c|c|c|c|c|c|c|c|}
\hline \multirow[t]{3}{*}{$\mathrm{SN}$} & \multirow[t]{3}{*}{ VDCs } & \multirow{3}{*}{$\begin{array}{c}\text { Total no. of } \\
\text { Samples }\end{array}$} & \multicolumn{6}{|c|}{ Concentration of Arsenic in ppb } & \multirow{3}{*}{$\begin{array}{c}\text { Highest } \\
\text { Conc } \\
\text { in ppb }\end{array}$} \\
\hline & & & \multicolumn{2}{|c|}{$0-10$} & \multicolumn{2}{|c|}{ 11-50 } & \multicolumn{2}{|r|}{$>\mathbf{5 0}$} & \\
\hline & & & No. & $\%$ & No. & $\%$ & No. & $\%$ & \\
\hline 1 & Gobardiha & 686 & 644 & 93.88 & 30 & 4.37 & 12 & 1.75 & 150 \\
\hline 2 & Gangaparas & 1116 & 1076 & 96.42 & 27 & 2.42 & 13 & 1.16 & 80 \\
\hline 3 & Gadhwa & 1468 & 1450 & 98.77 & 16 & 1.09 & 2 & 0.14 & 74 \\
\hline 4 & Bela & 676 & 659 & 97.49 & 11 & 1.63 & 6 & 0.89 & 150 \\
\hline 5 & Satbariya & 1060 & 1043 & 98.4 & 15 & 1.42 & 2 & 0.19 & 56 \\
\hline 6 & Dharna & 853 & 837 & 98.12 & 13 & 1.52 & 4 & 0.47 & 80 \\
\hline 7 & Saudiyar & 1708 & 1696 & 99.30 & 10 & 0.59 & 2 & 0.12 & 51 \\
\hline 8 & Dhikpur & 1005 & 990 & 98.51 & 12 & 1.19 & 3 & 0.3 & 51 \\
\hline 9 & Duruwa & 914 & 902 & 98.69 & 11 & 1.20 & 1 & 0.11 & 60 \\
\hline 10 & Dhanauri & 738 & 733 & 99.32 & 4 & 0.54 & 1 & 0.14 & 75 \\
\hline
\end{tabular}
contain above $50 \mathrm{ppb}$ and remaining VDCs contain no arsenic concentration in Ground Water. A case of severe arsenicosis was identified in Bela VDC. (Table $1 \&$ 2)

Table 1: Status of Arsenic in VDCs having concentration above $50 \mathrm{ppb}$

More than $90 \%$ of Tubewells were safe in each VDC. Gobardiha possesses the highest number of arsenic affected TW and DW above 50 ppb with the percentage of 1.75 followed by Gangaparaspur with $1.16 \%$. 
Figure 1: Graphical Representation of Arsenic status in ten VDCs.

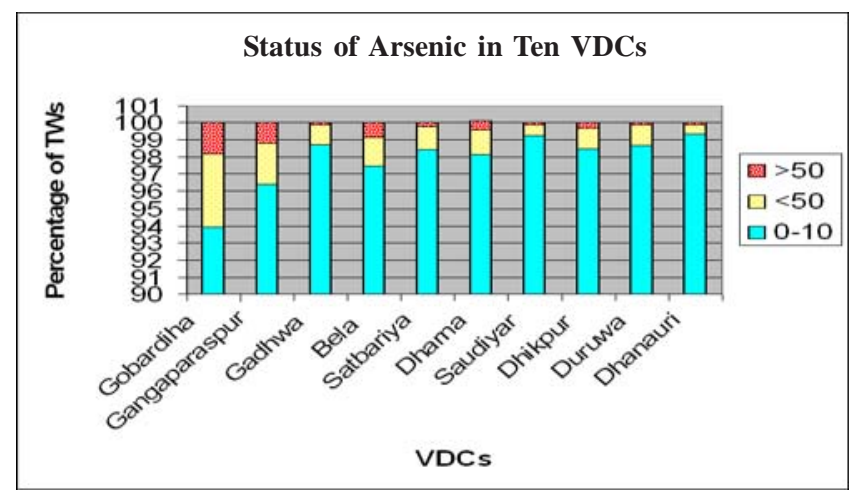

Highest Arsenic concentration was plotted against VDC and following graph was obtained.

Figure 2: Highest Concentration of Arsenic in Different VDCs.

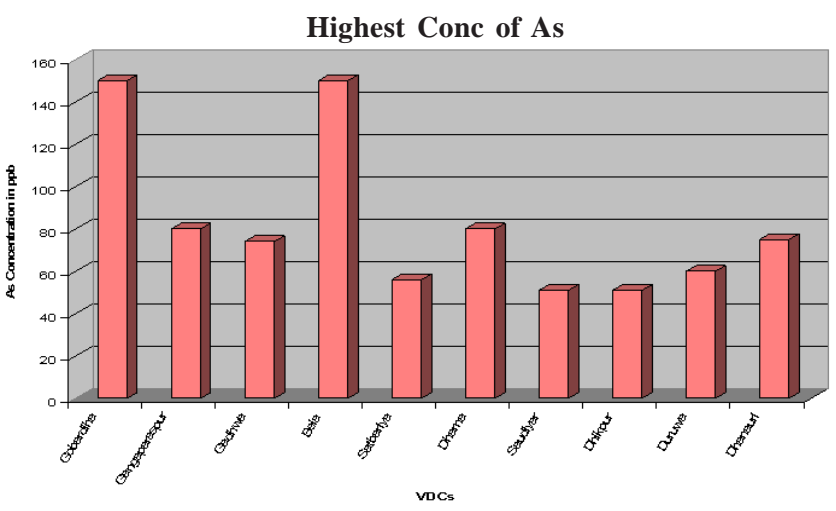

Among highly Arsenic contaminated VDCs, the highest concentration of Arsenic of 150 ppb was found in two VDCs namely Bela and Gobardiha. Moreover, an Arsenicosis patient was identified in Bela VDC.
Figure 3: Comparative Concentration of four metals.

\section{Comparative Plot of Probable Metal Contaminants}

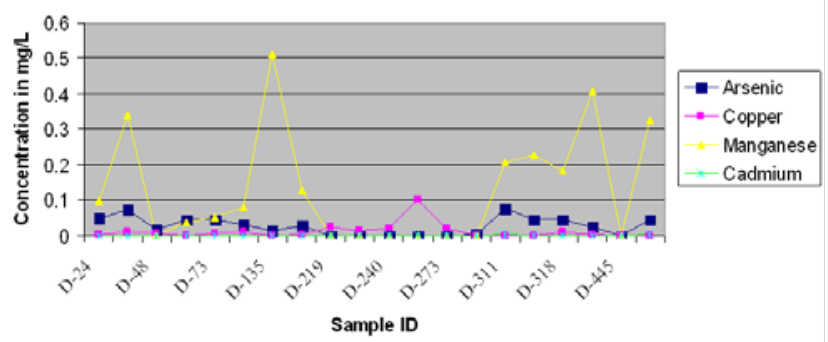

Statistical tools were employed to ascertain probable correlation between Iron and Arsenic and no significant correlation was found.

\section{CONCLUSIONS AND RECOMMENDATION}

On the basis of study, Dang district was found to be moderately affected by arsenic contamination in ground water with almost $0.2 \%$ of total Tube Wells containing Arsenic concentration transcending National Drinking Water Quality Standard Value of $0.05 \mathrm{mg} / \mathrm{L}$. A case of severe Arsenicosis was identified in Bela VDC. So, possible means of mitigation is necessary for the inhabitants of highly affected VDCS. Furthermore, other metals like iron and manganese were found to associate along with arsenic in high concentration. But the correlation among these metals could not be figured out in a significant manner. In future, some large scale research can be conducted to find out such correlation.

Table2: AAS analysis of probable Heavy Metal contaminants.

\begin{tabular}{|l|l|c|c|c|c|c|}
\hline \multirow{2}{*}{ S.N. } & \multirow{2}{*}{ Sample ID } & \multicolumn{5}{|c|}{ Concentration of Metals in mgL $^{-1}$, analyzed by AAS } \\
\cline { 3 - 7 } & & Arsenic & Iron & Copper & Manganese & Cadmium \\
\hline 1 & D-24 & 0.048 & 2.69 & 0.005 & 0.097 & 0.000 \\
\hline 2 & $\mathrm{D}-30$ & 0.072 & 2.31 & 0.009 & 0.339 & 0.000 \\
\hline 3 & $\mathrm{D}-48$ & 0.016 & 0.13 & 0.006 & 0.000 & 0.000 \\
\hline 4 & $\mathrm{D}-50$ & 0.046 & 2.72 & 0.000 & 0.037 & 0.000 \\
\hline 5 & $\mathrm{D}-73$ & 0.045 & 2.29 & 0.008 & 0.052 & 0.000 \\
\hline 6 & $\mathrm{D}-75$ & 0.032 & 3.01 & 0.010 & 0.079 & 0.000 \\
\hline 7 & $\mathrm{D}-135$ & 0.014 & 1.93 & 0.000 & 0.513 & 0.001 \\
\hline 8 & $\mathrm{D}-147$ & 0.028 & 2.17 & 0.005 & 0.126 & 0.000 \\
\hline 9 & $\mathrm{D}-219$ & 0.001 & 0.50 & 0.024 & 0.000 & 0.000 \\
\hline 10 & $\mathrm{D}-227$ & 0.000 & 0.15 & 0.015 & 0.000 & 0.000 \\
\hline 11 & $\mathrm{D}-240$ & 0.001 & 0.63 & 0.020 & 0.000 & 0.000 \\
\hline 12 & $\mathrm{D}-243$ & 0.0004 & 0.23 & 0.101 & 0.000 & 0.000 \\
\hline 13 & $\mathrm{D}-273$ & 0.001 & 0.17 & 0.020 & 0.000 & 0.000 \\
\hline 14 & $\mathrm{D}-275$ & 0.002 & 0.13 & 0.000 & 0.000 & 0.000 \\
\hline 15 & $\mathrm{D}-311$ & 0.078 & 8.43 & 0.000 & 0.208 & 0.002 \\
\hline 16 & $\mathrm{D}-316$ & 0.047 & 5.18 & 0.000 & 0.228 & 0.000 \\
\hline 17 & $\mathrm{D}-318$ & 0.044 & 4.81 & 0.012 & 0.184 & 0.000 \\
\hline 18 & $\mathrm{D}-342$ & 0.025 & 5.86 & 0.004 & 0.407 & 0.001 \\
\hline 19 & $\mathrm{D}-445$ & 0.0004 & 0.17 & 0.000 & 0.000 & 0.000 \\
\hline 20 & $\mathrm{D}-509$ & 0.047 & 11.01 & 0.0003 & 0.326 & 0.002 \\
\hline
\end{tabular}

Among 540 samples brought to central laboratory, 20 were selected randomly for the assessment of other probable heavy metal contaminants like iron, copper, Manganese and cadmium. Iron was found to be above Nepal Water Quality standard Value of 0.3mg/L in 14 samples with the highest concentration of $11.1 \mathrm{mg} / \mathrm{L}$, Manganese (Nepal Standard Value: $0.2 \mathrm{mg} / \mathrm{L}$ ) in 6 samples with highest concentration of $0.513 \mathrm{mg} / \mathrm{L}$. Other metals viz. copper and cadmium were found to be within Nepal Water Quality standard values of $1.0 \mathrm{mg} / \mathrm{L}$ and $0.003 \mathrm{mg} / \mathrm{L}$ respectively. 


\section{REFERENCES}

1. APHA, AWWA, and WEF. 2005. Standard methods for analysis of water and wastewater, $21^{\text {st }}$ edition, APHA, Washington D C.

2. Mendham, J.C., Denny, R.C. et al. 2006. Vogel's text book of quantitative chemical analysis, $6^{\text {th }}$ edition, Pearson Education Asia, Singapore.

3. Lee, J.D. 1999. Concise Inorganic Chemistry, $5^{\text {th }}$ edition, Blackwell Sciences Limited, India.

4. Huheey, James, E. and Keiter, Ellen A. 2000. Inorganic Chemistry: Principles of Structure and Reactivity, $4^{\text {th }}$ edition, Addison Wesley Publication Company, Menlo Park, California.

5. Nicholas, Norman C. 1998. Chemistry of Arsenic, Antimony and Bismuth, Springer. Pp. 50. ISBN 9780751403893. http:// books.google.de/books?id=vVhpurkfeN4C.
6. WHO. 2004. Guidelines for drinking water quality, $3^{\text {rd }}$ edition, volume 1, World Health Organization, Geneva.

7. Sah, R.B.and Shrestha, R. 2005. Journal of Stratigraphic Association of Nepal. 5: 1.

8. DWSS/UNICEF. 2002. A study on health effects of arsenic contaminated drinking water in Nawalparasi district, Nepal. A report ENPHO, Kathmandu, Nepal.

9. NASC. 2005. Summary of known arsenic occurrence in GW in Nepal. National Arsenic Steering Committee, Nepal.

10. Khadka, M.S. and Shrestha, M.K. 2006. Standard practices for arsenic testing and status of analytical laboratory in nepal, workshop on the role of environmental performance verification for safe water in Nepal, Kathmandu, Nepal. 